\begin{tabular}{ccl}
\hline Jurnal Teknologi Kimia Unimal & $\begin{array}{l}\text { Jurnal } \\
\text { Teknologi } \\
\text { Kimia } \\
\text { Unimal }\end{array}$ \\
\hline
\end{tabular}

\title{
Analisa Aliran Udara Panas pada Drying Chamber Raw Mill PT. Semen Padang menggunakan Computational Fluid Dynamic (CDF)
}

\section{Fajrida Afrina}

Jurusan Teknik Kimia, Fakultas Teknik, Universitas Malikussaleh Kampus Utama Cot Teungku Nie Reuleut, Muara Batu, Aceh Utara - 24355

Korespondensi: HP: 0823-8451-4219, e-mail: afajrida@yahoo.com

\begin{abstract}
Abstrak
Drying chamber adalah alat pengering bahan baku semen yang akan digiling dalam raw mill. Keefektifan kerja raw mill sangat dipengaruhi oleh sistem pengeringan pada bahan baku yang akan digiliing. Pengeringan di dalam drying chamber ini menggunakan udara panas dari kiln exhaust gas aliran ducting string B. Semakin kering bahan akan semakin mudah proses penggilingan. Heat transfer dari fluida ke bahan yang akan dkeringkan sangat penting agar diperoleh pengeringan yang optimum. Penelitian ini dilakukan dengan tujuan untuk mengetahui sacara teknis faktor yang mempemharuhi heat transfer dari udara pengering ke bahan yang dikeringkan dengan bantuan aplikasi computational fluid dynamic (CFD). Hasil simulasi yang dilakukan menggunakan CFD adalah heat transfer berbanding lurus dengan temperature dan velocity udara pengering, namun berbanding terbalik dengan waktu tinggal udara dalam drying chamber.Heat transfer optimum yang diperoleh pada penelitian ini adalah pada perlakuan velocity $15 \mathrm{~mm} / \mathrm{s}$, temperature 300 0C yaitu $901.480 \mathrm{Btu} / \mathrm{s}$.
\end{abstract}

Kata kunci: CFD, drying chamber, heat transfer, velocity, temperatur

\section{Pendahuluan}

Alat utama yang digunakan dalam proses penggilingan dan pengeringan bahan baku pembuatan semen terdiri dari dua jenis mill yaitu horizontal mill (tube mill) dan vertical mill. Media pengeringannya adalah udara panas yang berasal dari gas panas buangan kiln dengan temperature $220{ }^{\circ} \mathrm{C}-300{ }^{\circ} \mathrm{C}$. Volume udara yang tersedia dari kiln exhaust gas aliran ducting SP string $\mathrm{B}$ adalah sebesar $757,795 \mathrm{~m}^{3} / \mathrm{h}$. diinjeksikan ke raw mill indarung IV hanya sekitar $122,217 \mathrm{~m}^{3} / \mathrm{h}$ 
dank e coal mill sebesar 68,266 m3/h, kemudian sisanya dibuang ke udara melewati proses pendinginan di gas conditioning tower (GCT). Udara panas tersebut juga berfungsi sebagai media pembawa bahan-bahan yang telah halus menuju alat proses selanjutnya (Firdaus, 2007).

Proses penggilingan dan pengeringan bahan baku pada horizontal mill adalah dengan cara Material yang akan digiling dimasukkan bersamaan dengan aliran udara panas berasal dari suspension preheater yang ditarik oleh mill fan, sehingga di dalam tube mill selain terjadi proses penggilingan juga terjadi proses pengeringan. Tube mill untuk raw mill ini terdiri dari 3 ruangan, yaitu drying chamber, kamar I dan kamar II. Pada drying chamber dipasang lifter yang berfungsi untuk mengangkat dan menghamburkan material sehingga proses pengeringan dapat berlangsung dengan efektif karena luas permukaan material yang kontak dengan gas panas bertambah besar. Semakin tinggi temperatur udara di dalam drying chamber maka semakin bagus hasil pengeringan material, semakin bagus pengeringan material dalam drying chamber maka semakin mudah proses penggilingan pada chamber I dan diharapkan lebih efisien kerjanya raw mill horizontal (Varma, dkk 2013).

\section{Bahan dan Metode}

\subsection{Peralatan dan Bahan}

Adapun peralatan yang digunakan dalam penelitan ini adalah: Satu unit laptop ASUS, Processor intel(R) Celeron(R) CPU N2840 @ 2.16Hz 2.16 GHz, 64-bit Operating System juga menggunakan Software Autodesk CFD 2016. Software autodesk inventor 2014. Software pelengkap Microsoft Office.

\subsection{Variabel Penelitian}

Ada beberapa variabel yang berpengaruh dalam penelitian ini yaitu variabel tetap, variabel bebas dan variabel terikat. Adapun variabelnya sebagai berikut: 


\subsubsection{Variabel Tetap}

Adapun variabel tetap yang digunakan adalah:

a. Diameter dryng chamber $(5.000 \mathrm{~mm})$

$b$. Bahan yang akan dikeringkan: silica stone, iron sand, lime stone, clay.

c. Pressure: $2 \mathrm{~atm}$

\subsubsection{Variabel Bebas}

Adapun variabel bebas yang digunakan adalah:

a. Velocity udara panas : 5, 10, 15, 20, $25(\mathrm{~mm} / \mathrm{s})$

b. Temperatur udara panas : 220, 240, 260, 280, $300\left({ }^{\circ} \mathrm{C}\right)$

\subsubsection{Variabel Terikat}

Adapun variabel terikat yang digunakan adalah:

a. Distribusi penyebaran suhu dalam drying chamber

b. Heat transfer

c. Volume udara panas yang dibutuhkan untuk heat transfer optimum.

\subsection{Prosedur Penelitian}

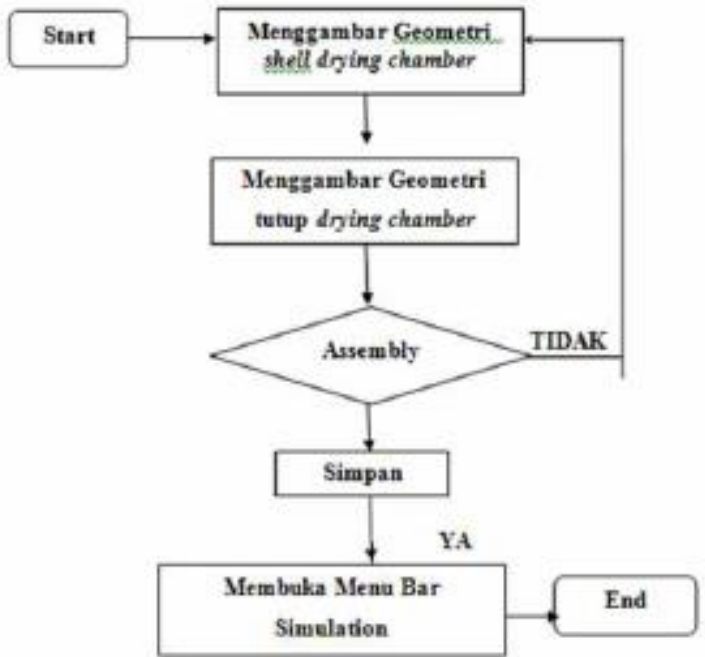

Gambar 1 Bagan alir prosedur inventor 
Proses simulasi untuk penelitian ini ada beberapa langkah yang sebelumnya dimulai dari pembentukan geometri pada software autodesk Inventor dapat dilihat pada diagram alir Gambar 1 dan simulasi dengan menggunakan software autodesk CFD dapat dilihat pada diagram alir Gambar 2.

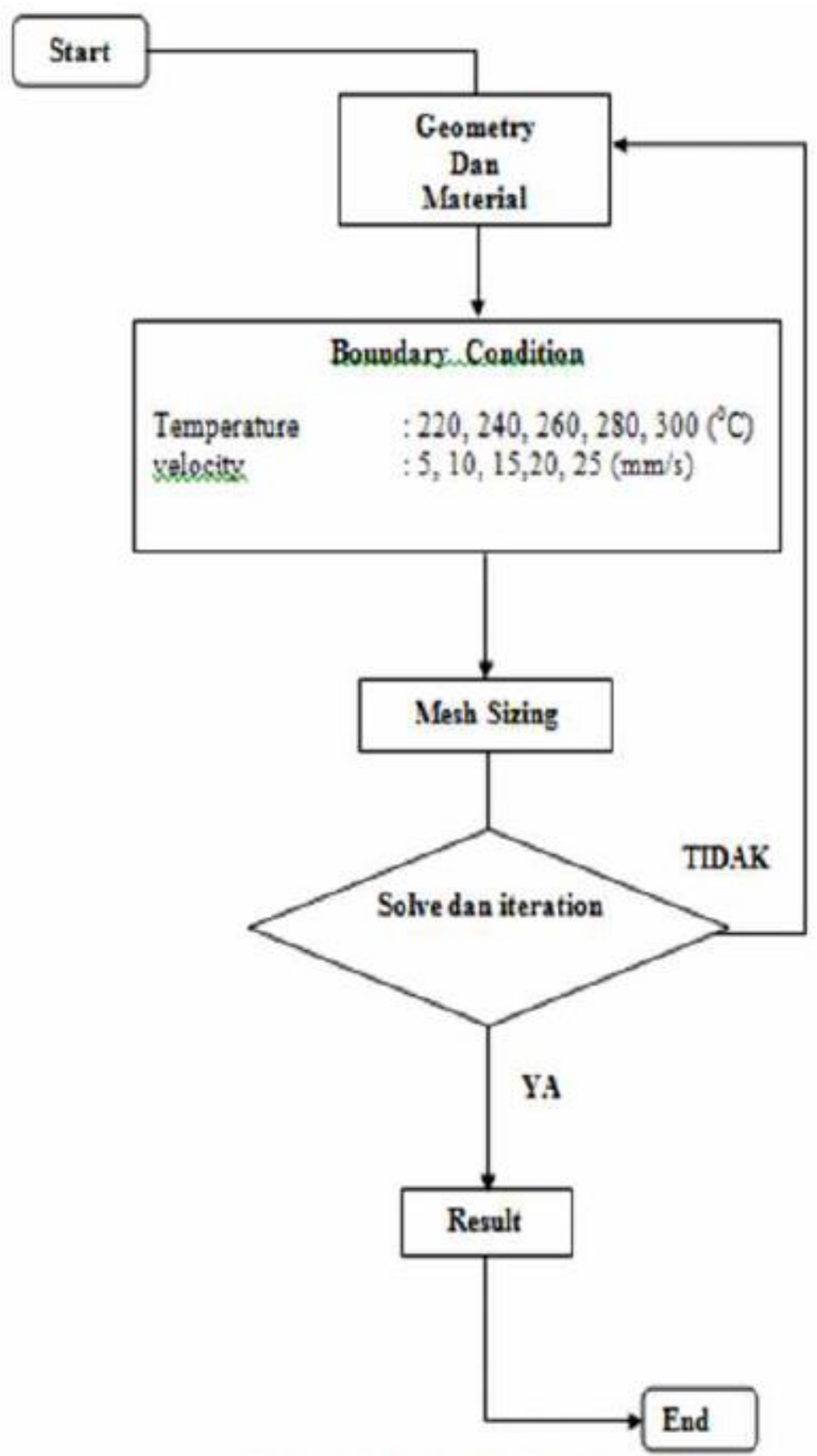

Gambar 2 Bagan alir prosedur CFD 


\section{Hasil dan Pembahasan}

\subsection{Analisa aliran udara panas pengering dengan metode simulasi $C F D$}

Penggambaran model drying chamber dilakukan menggunakan software autodesk inventor 2014. Desainya dapat dilihat pada Gambar 3.

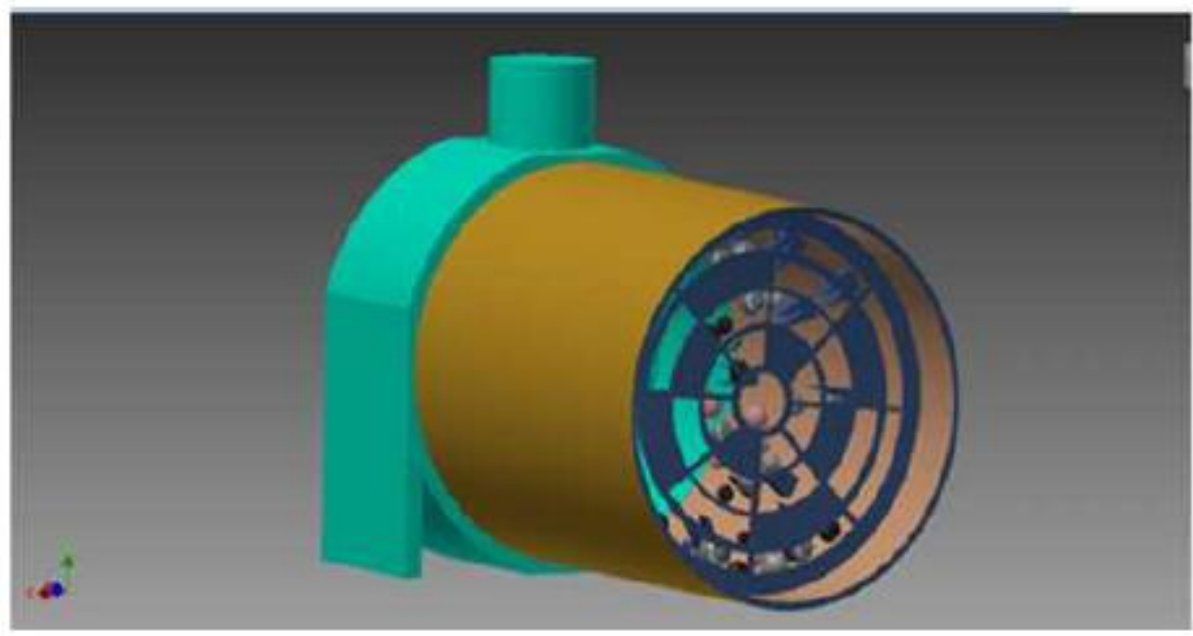

Gambar 3 Drying chamber dalam autodesk inventor

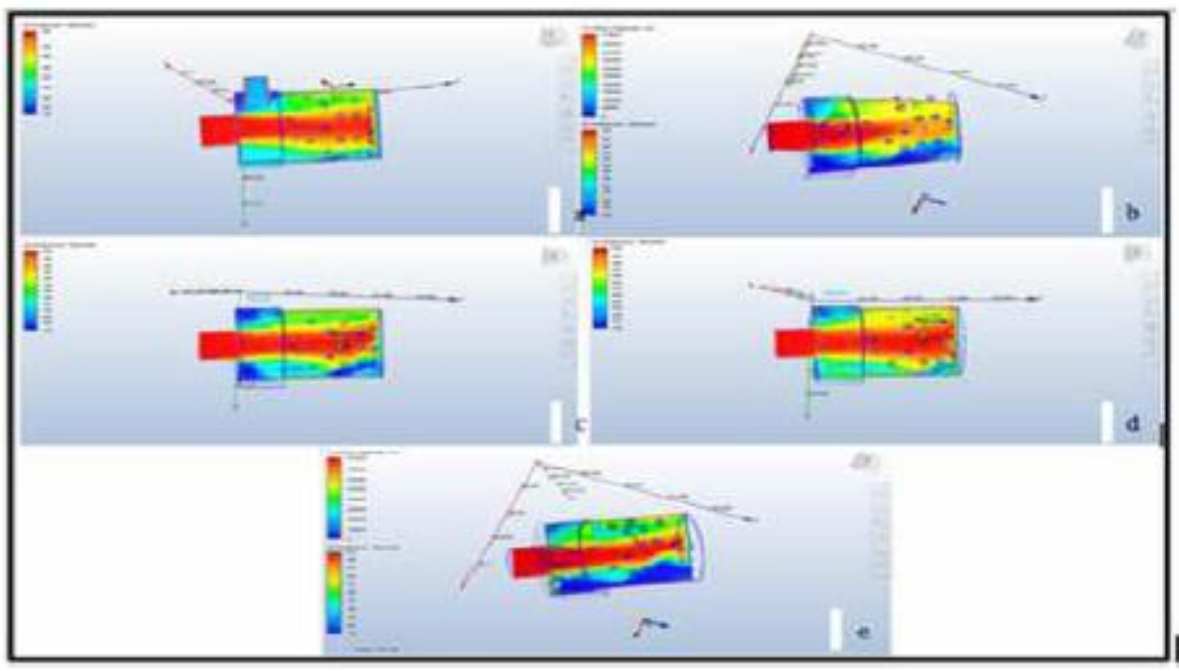

Gambar 4 Distribusi suhu dalam drying chamber (a) velocity $5 \mathrm{~mm} / \mathrm{s}$, (b) velocity $10 \mathrm{~mm} / \mathrm{s} \mathrm{(c)} \mathrm{velocity} 15 \mathrm{~mm} / \mathrm{s}$ (d) velocity $20 \mathrm{~mm} / \mathrm{s}(\mathrm{e})$ velocity $25 \mathrm{~mm} / \mathrm{s}$.

Gambar 4 menunjukkan distribusi suhu yang terjadi pada setiap sudut drying chamber berdasarkan velocity udara panas yang diinjeksikan pada 
Table 1 Hasil analisa udara panas pengering pada drying chamber

\begin{tabular}{|l|l|l|l|l|c|}
\hline run & Velocity $(\mathrm{mm} / \mathrm{s})$ & $\mathrm{T}\left({ }^{\circ} \mathrm{C}\right)$ & $\begin{array}{l}\text { Heat transfer } \\
(\mathrm{Btu} / \mathrm{s})\end{array}$ & Volume $\mathrm{m}^{5} / \mathrm{h}$ & $\begin{array}{l}\text { Waktu } \\
\text { tinggal (m) }\end{array}$ \\
\hline 1 & 5 & 220 & 494.610 & 208,7222411 & 26 \\
\hline 2 & 5 & 240 & 601.650 & 208,7222411 & 26 \\
\hline 3 & 5 & 260 & 639.790 & 208,7222411 & 26 \\
\hline 4 & 5 & 280 & 689.780 & 208,7222411 & 26 \\
\hline 5 & 5 & 300 & 750.870 & 208,7222411 & 26 \\
\hline 6 & 10 & 220 & 497.320 & 417,4434203 & 13 \\
\hline 7 & 10 & 240 & 614.480 & 417,4434203 & 13 \\
\hline
\end{tabular}

\begin{tabular}{|l|l|l|l|l|l|}
\hline 8 & 10 & 260 & 648.940 & 417,4434203 & 13 \\
\hline 9 & 10 & 280 & 696.610 & 417,4434203 & 13 \\
\hline 10 & 10 & 300 & 778.280 & 417,4434203 & 13 \\
\hline 11 & 15 & 220 & 527.480 & 626,1669003 & 9 \\
\hline 12 & 15 & 240 & 663.180 & 626,1669003 & 9 \\
\hline 13 & 15 & 260 & 683.240 & 626,1669003 & 9 \\
\hline 14 & 15 & 280 & 740.470 & 626,1669003 & 9 \\
\hline 15 & 15 & 300 & 901.480 & 626,1669003 & 9 \\
\hline 16 & 20 & 220 & 499.060 & 834,8886105 & 6 \\
\hline 17 & 20 & 240 & 651.970 & 834,8886105 & 6 \\
\hline 18 & 20 & 260 & 669.200 & 834,8886105 & 6 \\
\hline 19 & 20 & 280 & 721.660 & 834,8886105 & 6 \\
\hline 20 & 20 & 300 & 825.000 & 834,8886105 & 6 \\
\hline 21 & 25 & 220 & 498.070 & $1.043,609141$ & 5 \\
\hline 22 & 25 & 240 & 651.160 & $1.043,609141$ & 5 \\
\hline 23 & 25 & 260 & 668.760 & $1.043,609141$ & 5 \\
\hline 24 & 25 & 280 & 713.340 & $1.043,609141$ & 5 \\
\hline 25 & 25 & 300 & 811.330 & $1.043,609141$ & 5 \\
\hline
\end{tabular}

temperatur $300{ }^{0} \mathrm{C}$ yang dianalisa menggunakan software autodesk simulation CFD. Gambar 4 menunjukkan bahwa warna biru tua suhunya antara 176-240 ${ }^{\circ} \mathrm{F}$, biru muda suhunya antara $240-300{ }^{\circ} \mathrm{F}$, hijau suhunya antara $300-380{ }^{\circ} \mathrm{F}$, kuning suhunya antara $380-400{ }^{\circ} \mathrm{F}$, orange suhunya antara $400-450{ }^{\circ} \mathrm{F}$, hijau suhunya antara $450-500{ }^{\circ} \mathrm{F}$.

Gambar 4 menjelaskan bahwa distribusi suhu optimum adalah pada velocity $15 \mathrm{~mm} / \mathrm{s}$ sesuai dengan data hasil pengamatan pada Tabel 1. Heat transfer 
optimum diperoleh pada velocity $15 \mathrm{~mm} / \mathrm{s}$, temperatur $300{ }^{\circ} \mathrm{C}$, serta volume udara panas sebesar $626 \mathrm{~m}^{3} / \mathrm{h}$.

\subsection{Analisa aliran udara panas pengering pada drying chamber dengan heat transfer dan volume rate serta efisiensi pengeringan}

Penelitian yang telah dilakukan mendapatkan hasil heat transfer dan volume udara pengering yang dibutuhkan seperti pada Tabel 1. Tabel 1 membuktikan bahwa velocity dan suhu udara panas yang diinjeksikan ke dalam drying chamber mempengaruhi heat transfer dari udara ke bahan yang dikeringkan dan volume udara yang dibutuhkan untuk pengeringan. Adapun hubungan velocity dan temperatur terhadap heat transfer seperti terlihat pada Gambar 5.

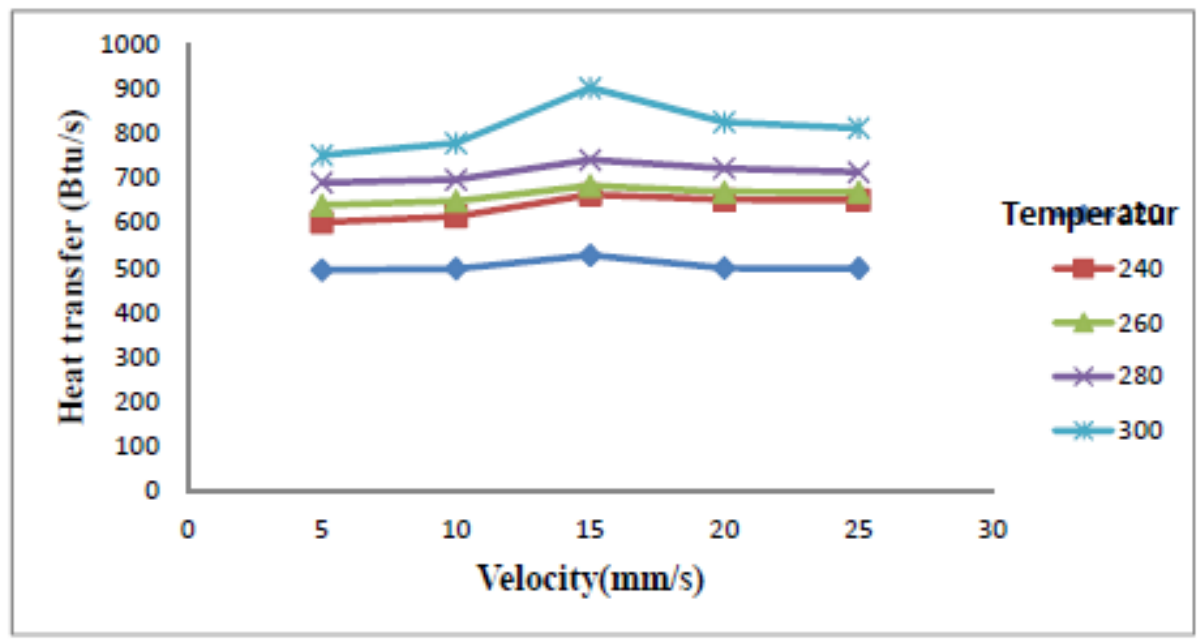

Gambar 5 Grafik hubungan antara velocity dan temperatur terhadap heat transfer

Hasil yang dipaparkan di atas dapat diketahui bahwa heat transfer semakin meningkat sering meningkatnya temperature udara panas yang diinjeksikan, heat transfer optimum dari hasil pnelitian ini diperoleh sebesar $901.480 \mathrm{btu} / \mathrm{s}$ dengan velocity udara pengering $15 \mathrm{~mm} / \mathrm{s}$ dan temperature $300{ }^{\circ} \mathrm{C}$. dengan volume udara pengering yang dibutuhkan sebesar $626,1669003 \mathrm{~m} 3 / \mathrm{h}$, serta waktu tinggal udara dalam drying chamber selama 9 menit. 
Raw mill Indarung IV PT Semen Padang volume udara yang tersedia dari kiln exhaust gas aliran ducting SP string B adalah sebesar 757,795 m3/h. Udara panas diinjeksikan ke raw mill indarung IV hanya sekitar 122,217 m3/h dan ke coal mill sebesar 68,266 m3/h, kemudian sisanya dibuang ke udara melewati proses pendinginan di gas conditioning tower (GCT). Udara panas yang dibuang tersebutlah yang kita manfaatkan untuk memenuhi kebutuhan udara panas drying chamber agar tercapai heat transfer maksimum dan pengeringan bahan baku yang akan digiling lebih sempurna.

\section{Simpulan dan Saran}

\subsection{Simpulan}

Temperatur udara pengering mengalami penurunan sepanjang perjalanan sampai ke outlet karena mengalami perpindahan panas dari fluida ke bahan yang akan dikeringkan. Heat transfer optimum yang diperoleh adalah $901.480 \mathrm{btu} / \mathrm{s}$ dengan temperature $3000 \mathrm{C}$ dan velocity $5 \mathrm{~mm} / \mathrm{s}$. Volume udara pengering yang dibutuhkan untuk mendapatkan heat transfer optimum adalah sebesar $626,1669003 \mathrm{~m} 3 / \mathrm{h}$. Waktu tinggal yang baik digunakan untuk pencapaian heat transfer optimum adalah selama 9 menit.

\subsection{Saran}

Berdasarkan penelitian yang telah dilakukan maka disarankan pada manajemen Indarung IV PT. semen padang untuk memanfaatkan udara panas yang dibuang untuk mencukupi suplay udara panas pengering bahan baku yang dibutuhkan drying chamber. Selanjutnya saran untuk para peneliti berikutnya agar dapat menghitung efisiensi kerja alat pengering agar penelitian ini lebih sempurna lagi dan dapat bermanfaat.

\section{Daftar Pustaka}

Afdhal. 2016. Evaluasi Neraca Massa dan Energi Unit Kiln dan Kinerja Separator Unit Cement Mill Indarung V PT Semen Padang. Depok: 
Universitas Indonesia.

Firdaus, A. (2007). Proses Pembuatan Semen Pada PT. Holcim Indonesia Banten: Universitas Sultan Ageng Tirtayasa.

Gordon,L. 2012. CFD Software Calculation Underwater Speed For a Small Sub.California: Penton Media.

Hadi, S. P., Purwono, S., \& Fajar, T. 2014. Simulasi Aliran Fluida (Minyak) Pada Hydraulic Wave Energy Converter Menggunakan Pendekatan CFD Computational Fluid Dynamics. Surabaya: Institut Sepuluh November.

Hartono, F., Arizal. 2013. Computational Fluid Dynamic Analysis OF Turbojet. Bandung. Insstitut Teknologi Bandung.

Herliani, H., Fenny. 2017. Menghitung Neraca Massa \& Energi Coal Mill \& Cement Mill Serta Heat Consumption Klinker Unit Kiln di Pabrik Indarung V PT Semen Padang. Palembang: Universitas Sriwijaya.

Hendro. 2011. Pemodelan Computational Fluid Dynamics ( CFD ) Reaktor Pelat Sejajar Untuk Reaksi. Depok: Universitas Indonesia.

Novia, N., Faizal, M., \& Liana, S. 2004. CFD Modeling Of Waste Heat Recovery On The Rotary Kiln System in the Cement Industry. Palembang:Universitas Sriwijaya.

Sayma, A., Ventus. 2009. Computational Fluid Dynamics. Bookboon Permatasari, R., Annas, M. S., \& Ardian, B. (2015). Distribusi Temperatur Pada Microwave menggunakan Metode CFD. Banjarmasin: Universitas Trisakti

Varma, B. T. D. P., Sirisha, K. P. 2013. Study of Processing and Machinery in Cement Industry. Narsapur: International Journal of Engineering and Innovative Technology (IJEIT). 